\title{
Enzymatic creatinine assays allow estimation of glomerular filtration rate in stages 1 and 2 chronic kidney disease using CKD-EPI equation
}

\author{
Nils Kuster ${ }^{\mathrm{a}}$, Jean-Paul Cristol ${ }^{\mathrm{a}, *}$, Etienne Cavalier ${ }^{\mathrm{b}, \mathrm{c}}$, Anne-Sophie Bargnoux ${ }^{\mathrm{a}}$, Jean-Michel Halimi ${ }^{\mathrm{d}}$, \\ Marc Froissart ${ }^{\mathrm{e}}$, Laurence Piéroni ${ }^{\mathrm{f}}$, Pierre Delanaye ${ }^{\mathrm{b}}$, \\ on behalf of the Société Française de Biologie Clinique (SFBC)
}

a Department of Biochemistry, CHU Lapeyronie, Montpellier, France

${ }^{\mathrm{b}}$ Department of Nephrology-Dialysis-Transplantation, University of Liège, CHU Sart Tilman, Liège, Belgium

c Department of Clinical Chemistry, University of Liège, CHU Sart Tilman, Liège, Belgium

d Service de néphrologie, CHU Bretonneau, Tours, France

e Physiologie Rénale, Hôpital Européen Georges Pompidou, APHP, Paris, France

f Biochimie métabolique, Groupe hospitalier Pitié Salpêtrière, APHP, Paris, France

\section{A R T I C L E I N F O}

\section{Article history:}

Received 11 September 2013

Received in revised form 1 November 2013

Accepted 1 November 2013

Available online 10 November 2013

\section{Keywords:}

CKD-EPI

MDRD

Creatinine

Estimated glomerular filtration rate

Enzymatic assays

\begin{abstract}
A B S T R A C T
The National Kidney Disease Education Program group demonstrated that MDRD equation is sensitive to creatinine measurement error, particularly at higher glomerular filtration rates. Thus, MDRD-based eGFR above $60 \mathrm{~mL} / \mathrm{min} / 1.73 \mathrm{~m}^{2}$ should not be reported numerically. However, little is known about the impact of analytical error on CKD-EPI-based estimates. This study aimed at assessing the impact of analytical characteristics (bias and imprecision) of 12 enzymatic and 4 compensated Jaffe previously characterized creatinine assays on MDRD and CKD-EPI eGFR.

In a simulation study, the impact of analytical error was assessed on a hospital population of 24084 patients. Ability using each assay to correctly classify patients according to chronic kidney disease (CKD) stages was evaluated.

For eGFR between 60 and $90 \mathrm{~mL} / \mathrm{min} / 1.73 \mathrm{~m}^{2}$, both equations were sensitive to analytical error. Compensated Jaffe assays displayed high bias in this range and led to poorer sensitivity/specificity for classification according to CKD stages than enzymatic assays. As compared to MDRD equation, CKD-EPI equation decreases impact of analytical error in creatinine measurement above $90 \mathrm{~mL} / \mathrm{min} / 1.73 \mathrm{~m}^{2}$.

Compensated Jaffe creatinine assays lead to important errors in eGFR and should be avoided. Accurate enzymatic assays allow estimation of eGFR until $90 \mathrm{~mL} / \mathrm{min} / 1.73 \mathrm{~m}^{2}$ with MDRD and $120 \mathrm{~mL} / \mathrm{min} / 1.73 \mathrm{~m}^{2}$ with CKD-EPI equation.
\end{abstract}

(c) 2013 Elsevier B.V. All rights reserved.

\section{Introduction}

Chronic kidney disease (CKD) is associated with increased risk of cardiovascular events and overall mortality [1]. Since reliable methods to measure glomerular filtration rate (GFR) are expensive and difficult, it is assessed from serum creatinine (Scr) level in clinical practice [2]. However, Scr is also influenced by gender, age, muscle mass and ethnicity. To overcome these potential biases, equations have been developed

Abbreviations: CKD, chronic kidney disease; GFR, glomerular filtration rate; Scr, serum creatinine; eGFR, estimated glomerular filtration rate; MDRD, Modification of Diet in Renal Disease; CKD-EPI, Chronic Kidney Disease Epidemiology Collaboration; NKDEP, National Kidney Disease Education Program; IDMS, Isotope Dilution Mass Spectrometry; SFBC, Société Française de Biologie Clinique; KDIGO, Kidney Disease Improving Global Outcomes; TE, Total error.

* Corresponding author at: Department of Biochemistry, Lapeyronie Hospital, 191 Avenue du Doyen Gaston Giraud, 34295 Montpellier cedex 5, France. Tel.: +33 4673383 14; fax: + 33467338393 .

E-mail address: jp-cristol@chu-montpellier.fr (J.-P. Cristol). to correct Scr for these factors and therefore provide Scr-based estimated GFR (eGFR).

Modification of Diet in Renal Disease (MDRD) [3] and Chronic Kidney Disease Epidemiology Collaboration (CKD-EPI) [4] equations are automatically reported by laboratories in many countries. Scr is the most important variable in all these equations. Moreover, the relationship between Scr and GFR is exponential. Therefore, errors or imprecision in Scr measurements could strongly impact eGFR results, especially in the low Scr levels (high GFR values). As a result, the National Kidney Disease Education Program (NKDEP) working group recommended in 2006 not to report eGFR higher than $60 \mathrm{~mL} / \mathrm{min} / 1.73 \mathrm{~m}^{2}$ numerically [5]. At this time, two types of analytical errors were recognized regarding the measurement of Scr: the analytical imprecision which is inherent to any biological measurement and the bias which is the systematic error due to difference in calibration. Regarding this last point, improvements have been realized in the last years with a standardization of the measurement with the so-called Isotope Dilution Mass Spectrometry (IDMS) traceability. Even if many manufacturers 
claim their Scr assays are well IDMS traceable, we have in fact relatively few external and independent proofs of it. Recently, the "Société Française de Biologie Clinique (SFBC)" working group reported evaluations of currently available IDMS-traceable Scr assays, especially focusing on enzymatic and compensated Jaffe methods [6,7]. If correct traceability has been found for most enzymatic methods, the results were less accurate for the compensated Jaffe methods. Also regarding imprecision, there are reasons to think that enzymatic methods better perform than Jaffe methods which are susceptible to pseudochromogen interferences $[8,9]$. Therefore, we think that it still makes sense to study the analytical error of Scr and the impact on the GFR estimating equations. In other words, we want to check if, from an analytical point of view, reporting eGFR results above $60 \mathrm{~mL} / \mathrm{min} / 1.73 \mathrm{~m}^{2}$ is suitable in 2013 after improvements in standardization. Also, we analyzed potential differences between MDRD and CKD-EPI equations, the last one being now recommended by the Kidney Disease: Improving Global Outcomes (KDIGO) guidelines [10]. The CKD-EPI equation was still not available when NKDEP recommended not to report eGFR $>60 \mathrm{~mL} / \mathrm{min} / 1.73 \mathrm{~m}^{2}$ numerically.

\section{Material and methods}

\subsection{Creatinine measurements}

The analytical performances of 16 IDMS-traceable analyzers/Scr assays couples (12 enzymatic: Abbott/Abbott, Beckman Coulter/ Sentinel Diagnostics, FisherKonelab/Kone, Olympus AU 2700/ Diasys, Olympus AU 2700/Olympus, Olympus AU 2700/Randox, OrthoClinical/OrthoClinical, Roche Cobas 6000/Roche, Roche Modular/ Diasys, Roche Modular/Roche, Siemens Advia/Siemens, Siemens RXL/ Siemens; 4 compensated Jaffe: Olympus AU 2700/Compensated Jaffe, Roche Cobas 6000/Compensated Jaffe, Roche Modular/Compensated Jaffe, Siemens Advia/Compensated Jaffe) have been reported by the SFBC working group and compared to performances' characteristics proposed by NKDEP on the basis of biological variations of Scr [6,7]. Briefly, Scr level was assigned by gas chromatography IDMS (GCIDMS) in the Laboratoire National de Métrologie et d'Essais in five plasma pools ranging from 35.9 to $174.5 \mu \mathrm{mol} / \mathrm{L}$. The pools were then shipped to the laboratories involved in the study. For each assay, Scr level was determined for each pool in 3 laboratories, by 3 repeated measurements, 3 consecutive days. From these data, bias Assay $_{\text {(mean differ- }}$ ence from IDMS assigned value) and $\mathrm{sd}_{\text {Assay }}$ (standard deviation of the measurements) were computed.

\subsection{Study population}

Impact of analytical error on eGFR in was assessed using an unselected cohort of patients in whom Scr has been measured in the laboratory of biochemistry, Lapeyronie hospital, CHRU Montpellier, France. The measurements were performed between September, 1 st and December, 31st, 2012 using an enzymatic Roche assay on a Cobas 8000 modular analyzer. From an initial database of 87842 measurements, only patients aged over 18 years old and measured Scr levels lower than $200 \mu \mathrm{mol} / \mathrm{L}$ were selected in order to match with the SFBC Scr pool levels. For each patient, only the first measurement was kept, leading to a final population of 24084 patients.

\subsection{Ethical statement}

Patients Scr measurements were obtained from the routine laboratory database. No permission was required by our institution's Ethics Committee as the database was fully anonymous and no personal information was collected for this study.

\subsection{GFR estimation}

eGFR was computed using MDRD and CKD-EPI equations. Reexpressed four-variable MDRD equation for use with IDMS-traceable assays [11] is expressed as:

$$
\begin{aligned}
\mathrm{eGFR}= & 30849 \times \mathrm{Scr}^{-1.154} \times \text { Age }^{-0.203}[\times 0.742 \text { if Female }] \\
& \times[\times 1.212 \text { if Black }] .
\end{aligned}
$$

CKD-EPI equation [4] can be expressed in a single equation:

$$
\begin{aligned}
e G F R= & 141 \times \min \left(\frac{\mathrm{Scr}}{\kappa} ; 1\right)^{\alpha} \times \max \left(\frac{\mathrm{Scr}}{\kappa} ; 1\right)^{-1.209} \\
& \times 0.993^{\text {Age }}[\times 1.018 \text { if Female }][\times 1.159 \text { if Black } .
\end{aligned}
$$

With Scr in $\mu \mathrm{mol} / \mathrm{L}, \kappa$ is 62 for females and 80 for males, $\alpha$ is -0.329 for females and -0.411 for males, min indicates the minimum of $\mathrm{Scr} / \kappa$ or 1 and max indicates the maximum.

\subsection{Study design}

For each assay, estimations of bias and imprecision for Scr levels between 20 and $200 \mu \mathrm{mol} / \mathrm{L}$ were extrapolated from the results of the SFBC study.

\begin{tabular}{|c|c|c|c|c|c|}
\hline \multirow[t]{2}{*}{ Methode } & \multicolumn{5}{|l|}{ Total error (\%) } \\
\hline & $\begin{array}{l}\text { Pool } 1 \\
(35.9 \mu \mathrm{mol} / \mathrm{L})\end{array}$ & $\begin{array}{l}\text { Pool } 2 \\
(74.4 \mu \mathrm{mol} / \mathrm{L})\end{array}$ & $\begin{array}{l}\text { Pool } 3 \\
(97.9 \mu \mathrm{mol} / \mathrm{L})\end{array}$ & $\begin{array}{l}\text { Pool } 4 \\
(149.7 \mu \mathrm{mol} / \mathrm{L})\end{array}$ & $\begin{array}{l}\text { Pool } 5 \\
(174.5 \mu \mathrm{mol} / \mathrm{L})\end{array}$ \\
\hline Abbott/Abbott & 3.6 & 6.5 & 5 & 3.8 & 6.7 \\
\hline Beckman Coulter/Sentinel Diagnostics & 7 & 11.1 & 7.6 & 4.3 & 5.4 \\
\hline FisherKonelab/Kone & 19.5 & 7.4 & 5.9 & 8.3 & 5.3 \\
\hline Olympus AU 2700/Compensated Jaffe & 19.5 & 11.6 & 9.5 & 3.6 & 4.2 \\
\hline Olympus AU 2700/Diasys & 18.5 & 12.3 & 8.3 & 4.4 & 4.8 \\
\hline Olympus AU 2700/Olympus & 8.9 & 4.1 & 5.4 & 3 & 2.7 \\
\hline Olympus AU 2700/Randox & 12 & 8.8 & 8.9 & 6.7 & 8.4 \\
\hline OrthoClinical/OrthoClinical & 25.4 & 7 & 4.8 & 9 & 9.1 \\
\hline Roche Cobas 6000/Compensated Jaffe & 18.1 & 12.5 & 11.5 & 7.4 & 4.6 \\
\hline Roche Cobas 6000/Roche & 6.9 & 4.7 & 4 & 4.8 & 2.9 \\
\hline Roche Modular/Compensated Jaffe & 19.5 & 11.7 & 10.6 & 5.1 & 4.4 \\
\hline Roche Modular/Diasys & 10.9 & 6.5 & 6.1 & 3.9 & 3.7 \\
\hline Roche Modular/Roche & 8.3 & 3.2 & 3.9 & 2.7 & 2.7 \\
\hline Siemens Advia/Compensated Jaffe & 15.3 & 10.9 & 11.8 & 3.7 & 3.6 \\
\hline Siemens Advia/Siemens & 5.7 & 4.2 & 3.8 & 4.8 & 4.3 \\
\hline Siemens RXL/Siemens & 10.2 & 8.7 & 6.9 & 7.2 & 5.9 \\
\hline
\end{tabular}

Table 1

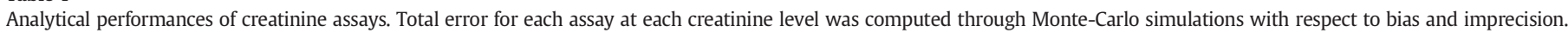
According to the National kidney Disease Education Program, optimum, desirable and minimum goals are 3.8\%, $7.6 \%$ and $11.4 \%$, respectively. 
Table 2

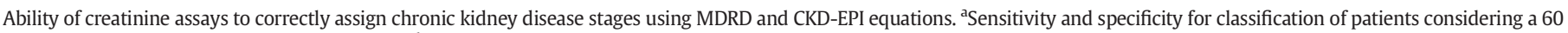

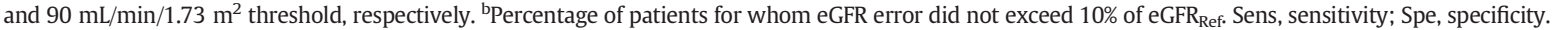

\begin{tabular}{|c|c|c|c|c|c|c|c|c|c|c|c|c|}
\hline \multirow[t]{3}{*}{ Methode } & \multicolumn{4}{|c|}{$60 \mathrm{~mL} / \mathrm{min} / 1.73 \mathrm{~m}^{2}$ cutoff $(\%)^{\mathrm{a}}$} & \multicolumn{4}{|c|}{$90 \mathrm{~mL} / \mathrm{min} / 1.73 \mathrm{~m}^{2}$ cutoff $(\%)^{\mathrm{a}}$} & \multicolumn{4}{|c|}{$\%$ patients with error below $10 \%$ of eGFR Ref } \\
\hline & \multicolumn{2}{|c|}{ MDRD } & \multicolumn{2}{|c|}{ CKD-EPI } & \multicolumn{2}{|l|}{ MDRD } & \multicolumn{2}{|c|}{ CKD-EPI } & \multicolumn{2}{|c|}{$\begin{array}{l}\text { Range } 60-90 \\
\mathrm{~mL} / \mathrm{min} / 1.73 \mathrm{~m}^{2}\end{array}$} & \multicolumn{2}{|c|}{$\begin{array}{l}\text { Range } 90-120 \\
\mathrm{~mL} / \mathrm{min} / 1.73 \mathrm{~m}^{2}\end{array}$} \\
\hline & Sens & Spe & Sens & Spe & Sens & Spe & Sens & Spe & MDRD & CKD-EPI & MDRD & CKD-EPI \\
\hline Abbott/Abbott & 89.4 & 100 & 90.4 & 100 & 92.2 & 99.9 & 93.7 & 99.9 & 100 & 100 & 100 & 100 \\
\hline Beckman Coulter/Sentinel Diagnostics & 97.3 & 97.6 & 97.3 & 98 & 96.7 & 85.9 & 97.5 & 91.1 & 88.2 & 90.6 & 85.8 & 96.5 \\
\hline FisherKonelab/Kone & 99.2 & 97.5 & 99.1 & 98 & 99.9 & 81.9 & 99.9 & 89.2 & 97.4 & 98.9 & 92.3 & 99.3 \\
\hline Olympus AU $2700 /$ Compensated Jaffe & 88.9 & 99.8 & 89.9 & 99.9 & 89.2 & 99 & 91.4 & 99.4 & 93.9 & 94.8 & 89.6 & 96.8 \\
\hline Olympus AU 2700/Diasys & 96 & 97.6 & 96.6 & 98.2 & 96.4 & 86.5 & 97.2 & 91.2 & 87.9 & 90.2 & 84.8 & 96.2 \\
\hline Olympus AU 2700/Olympus & 97.8 & 98.9 & 97.6 & 99.1 & 98.9 & 92.1 & 99 & 95.7 & 99.9 & 99.9 & 99.8 & 100 \\
\hline Olympus AU 2700/Randox & 98.6 & 97.4 & 98.9 & 97.9 & 98.3 & 87.5 & 98.9 & 91.8 & 96.3 & 96.5 & 95.7 & 99.1 \\
\hline OrthoClinical/OrthoClinical & 97.2 & 98.6 & 97 & 98.8 & 99.8 & 79.2 & 99.7 & 88.7 & 93.7 & 97.9 & 76 & 98.5 \\
\hline Roche Cobas 6000/Compensated Jaffe & 99.9 & 93.7 & 99.9 & 95 & 100 & 68.6 & 100 & 79 & 66.9 & 72.5 & 59.4 & 89.9 \\
\hline Roche Cobas 6000/Roche & 96.4 & 99.4 & 97.1 & 99.5 & 96.3 & 97.2 & 97.1 & 98.2 & 99.9 & 99.9 & 99.8 & 100 \\
\hline Roche Modular/Compensated Jaffe & 99.9 & 94.6 & 100 & 95.7 & 100 & 71.9 & 100 & 81.2 & 76.3 & 80.8 & 69.8 & 92.6 \\
\hline Roche Modular/Diasys & 98.5 & 98.2 & 98.6 & 98.6 & 99.4 & 88.7 & 99.4 & 92.9 & 99.5 & 99.6 & 98.9 & 99.8 \\
\hline Roche Modular/Roche & 99.7 & 98.8 & 99.4 & 99 & 99.8 & 92.5 & 99.9 & 95.5 & 100 & 100 & 100 & 100 \\
\hline Siemens Advia/Compensated Jaffe & 99.9 & 94.8 & 99.8 & 96 & 99.9 & 73.2 & 99.9 & 82.7 & 78.4 & 81.9 & 75.1 & 93.7 \\
\hline Siemens Advia/Siemens & 95.5 & 99.6 & 96 & 99.7 & 97.7 & 96.9 & 97.6 & 98.3 & 100 & 100 & 100 & 100 \\
\hline Siemens RXL/Siemens & 90.3 & 99.8 & 90.6 & 99.8 & 92 & 98.2 & 93.3 & 99 & 96.2 & 96.2 & 92.7 & 98.1 \\
\hline
\end{tabular}

In the study population, Scr measurement was carried out on a Cobas 8000 modular analyzer (c701 module) using the same reagent as the Roche enzymatic assay assessed by the SFBC study on a Cobas 6000 (c501 module). Although we cannot rule out a difference owing to platform and/or packaging, we assumed that the bias was similar in the two systems. Despite this limitation, subtracting the bias of Roche Cobas 6000/Enzymatic assay to the routine laboratory measurement provided a reasonably assumed unbiased distribution of Scr levels in the population, thereafter considered as the reference $\mathrm{Scr}\left(\mathrm{Scr}_{\mathrm{Ref}}\right)$ level for this study.

For each patient, Scr levels were simulated according to bias and imprecision of each assay, yielding to one simulated set of Scr levels by assay $\left(\mathrm{Scr}_{\text {Assay }}\right)$. Influence of $\mathrm{Scr}$ analytical error on GFR estimation was then assessed through comparison of reference Scr-based eGFR (MDRD ${ }_{\text {Ref }}$ and CKD-EPI Ref $_{\text {f }}$ and eGFR computed from $\mathrm{Scr}_{\text {Assay }}\left(\mathrm{MDRD}_{\text {Assay }}\right.$ and CKD$\mathrm{EPI}_{\text {Assay }}$ ). Furthermore, ability to correctly classify patients according to CKD stages was evaluated.

\subsection{Statistical analysis}

Total error (TE) was computed for each assay and pool was defined as the 95th percentile of the absolute errors in a random sample of size 10000 from a normal distribution with mean equal to the bias and standard deviation equal to imprecision of each assay.

Visual inspection of the data from previous SFBC studies [6,7] indicated that bias and imprecision were not linearly related to Scr levels. Bias and imprecision in the range of $20-200 \mu \mathrm{mol} / \mathrm{L}$ were extrapolated using locally-weighted polynomial regressions. $\mathrm{Scr}_{\mathrm{Ref}}$ was computed by subtracting bias observed for the instrument used in our laboratory to the results measured in patients. $\mathrm{Scr}_{\text {Assay }}$ was computed through random generation of values following a normal distribution with mean equal to $\mathrm{Scr}_{\text {Ref }}+$ Bias $_{\text {Assay }}$ and standard deviation equal to $\mathrm{Sd}_{\text {Assay }}$.

Median, 2.5th and 97.5th percentiles of the difference between eGFR Assay $_{\text {and }}$ eGFR $R_{\text {Ref }}$ were assessed using nonparametric quantile regression with B-splines (rqss, quantreg package). Ability to correctly

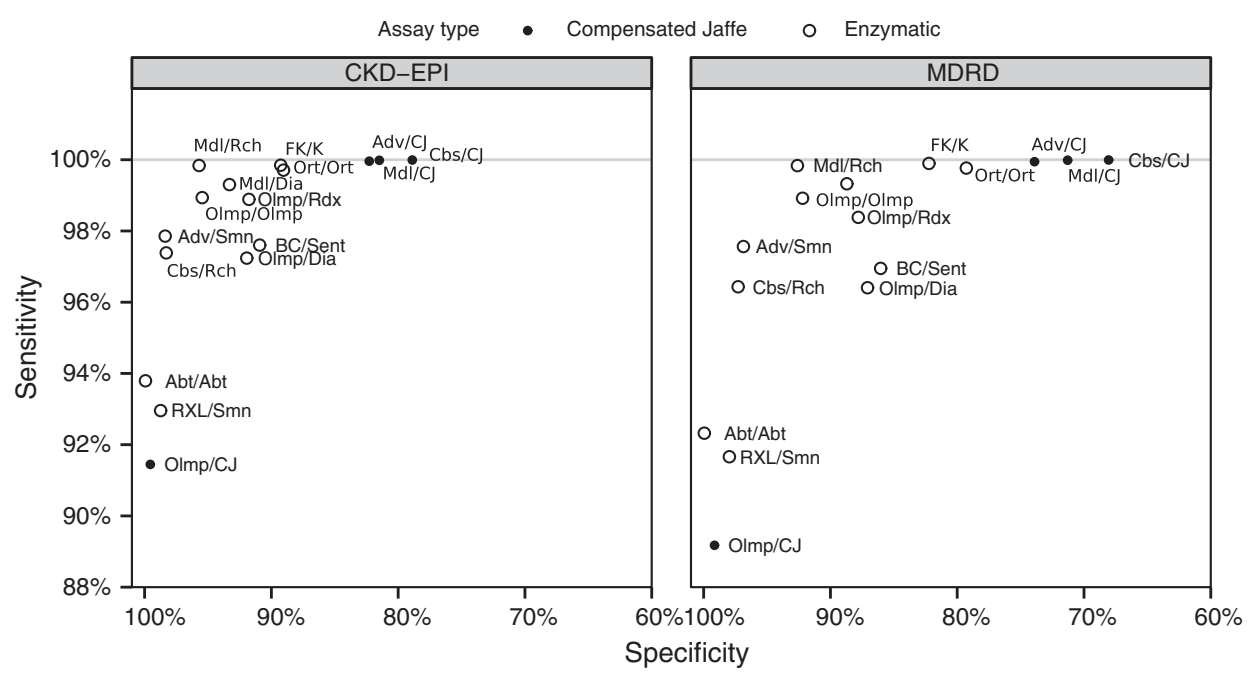

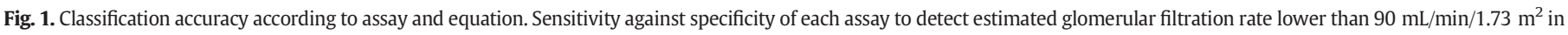

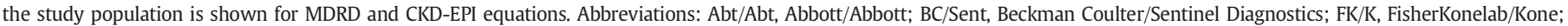

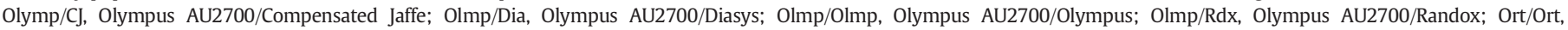

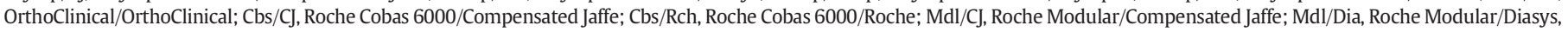
Mdl/Rch, Roche Modular/Roche; Adv/CJ, Siemens Advia/Compensated Jaffe; Adv/Smn, Siemens Advia/Siemens; RXL/Smn, Siemens RXL/Siemens. 
classify patients according to KDIGO CKD stages using each assay was assessed through computation of sensitivity and specificity to predict eGFR lower than 60 and $90 \mathrm{~mL} / \mathrm{min} / 1.73 \mathrm{~m}^{2}$. Accuracy was assessed as the percentage of estimates that differed by less than $10 \%$ from GFR $_{\text {Ref. }}$. All analysis was performed using R 2.15 (Vienna, Austria).

\section{Results}

Between September, 1st, 2012 and December, 31st, 2012, Scr was measured in 24084 patients aged over 18 years in the Department of Biochemistry, Lapeyronie University Hospital, Montpellier, France. Scr measurement was performed using a Roche enzymatic assay on a Cobas 8000 modular analyzer (Hoffman-La Roche, Basel, Switzerland). Mean age of patients was 55 years old (minimum - maximum, 18-105). Thirteen thousand height hundred six (57.3\%) patients were aged 18 to
60 years, 5810 (24.1\%), were aged 61 to 75 years and 4468 (18.6\%) were aged 76 years or older. Gender was male in 12049 patients (50.0\%). According to the routinely reported CKD-EPI based eGFR, 4000 (16.6\%) patients had eGFR $<60 \mathrm{~mL} / \mathrm{min} / 1.73 \mathrm{~m}^{2}, 8171$ (33.9\%) had eGFR in the range of $60-89 \mathrm{~mL} / \mathrm{min} / 1.73 \mathrm{~m}^{2}$ and 11913 (49.5\%) had eGFR greater than $90 \mathrm{~mL} / \mathrm{min} / 1.73 \mathrm{~m}^{2}$.

\subsection{Performances of currently available creatinine assays}

TE for each assay at each Scr pool level is shown in Table 1. Seven of the 16 assays respect the NKDEP minimum goal of $11.4 \%$ [5] at each Scr level, from which only 3 also respect the desirable threshold of $7.6 \%$. No assay presented a TE lower than that of the optimal 3.8\% goal at all Scr levels. Maximal error is frequently found at lowest Scr level (pool 1). At pool 2 level, 3 assays (Beckman Coulter/Sentinel Diagnostics, Roche

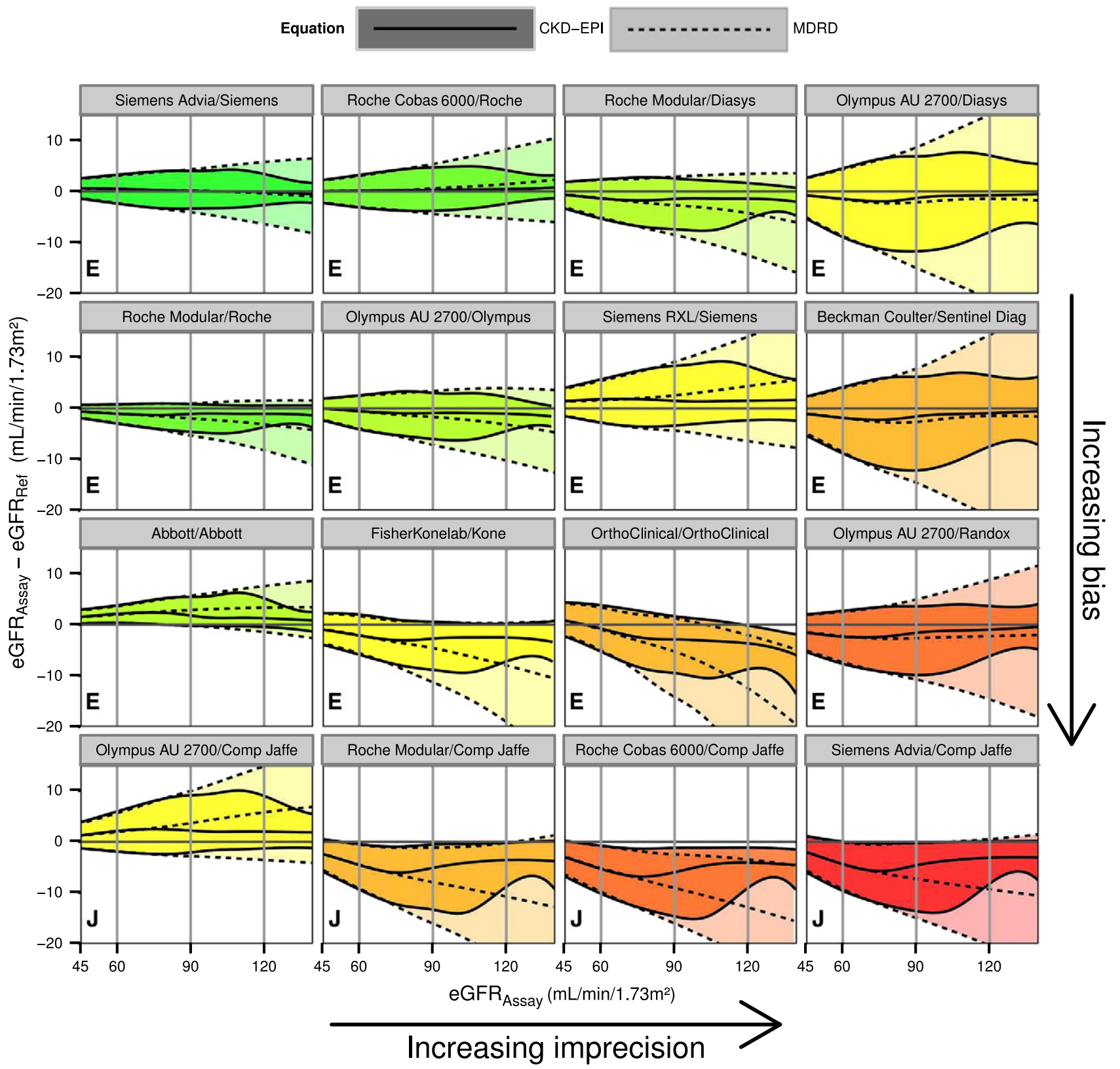

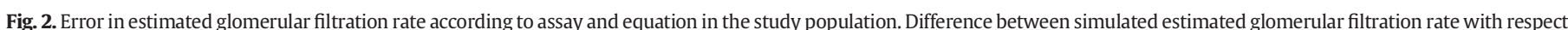

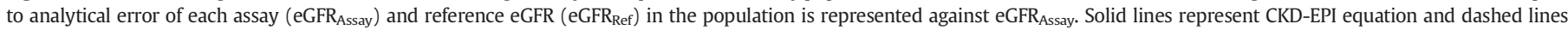

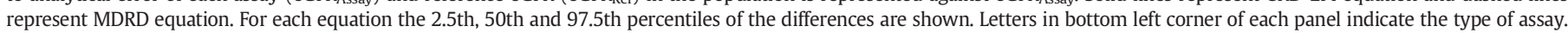
E: enzymatic assay, J: Compensated Jaffe assay. 
Modular/Compensated Jaffe, Roche Cobas 6000/Compensated Jaffe) presented TE greater than those of the minimum goal. Moreover, this minimum goal was not reached at pool 3 level with Siemens Advia/ Compensated Jaffe assay.

\subsection{Enzymatic creatinine assays improve GFR estimation above $60 \mathrm{~mL} / \mathrm{min} / 1.73 \mathrm{~m}^{2}$}

As shown in Table 2, in the range of $60-90 \mathrm{~mL} / \mathrm{min} / 1.73 \mathrm{~m}^{2}$, GFR was estimated with an error below $10 \%$ for the majority of patients with enzymatic assays using both equations (mean proportion, 97.5\% and $96.6 \%$ with CKD-EPI and MDRD, respectively). Compensated Jaffe assays did not allow this level of accuracy (mean proportion, $82.5 \%$ and $78.9 \%$ with CKD-EPI and MDRD, respectively).

As shown in Fig. 1, compensated Jaffe assays were associated with the lowest ability to correctly classify patients as having eGFR below $90 \mathrm{~mL} / \mathrm{min} / 1.73 \mathrm{~m}^{2}$, because of a lack of sensitivity (compensated Jaffe/Olympus AU2700) or specificity (Compensated Jaffe reagents on Siemens Advia, Roche Modular and Roche Cobas 6000 analyzers). By contrast, some enzymatic assays displayed both specificity and sensitivity above $95 \%$, with MDRD and CKD-EPI equations (Siemens Advia/Siemens and Roche Cobas 6000/Roche assays). At $60 \mathrm{~mL} / \mathrm{min} / 1.73 \mathrm{~m}^{2}$, a similar pattern was observed, although compensated Jaffe reagents on Siemens
Advia, Roche Modular and Roche Cobas 6000 analyzers yield to a better specificity (Table 2 ).

\subsection{CKD-EPI equation reduces impact of analytical error at higher glomerular filtration rate}

Error in eGFR caused by $\mathrm{Scr}$ analytical error in the study population is shown in Fig. 2. For eGFR below $75 \mathrm{~mL} / \mathrm{min} / 1.73 \mathrm{~m}^{2}$, error was nearly identical with MDRD or CKD-EPI equation. For eGFR equal to $60 \mathrm{~mL} / \mathrm{min} / 1.73 \mathrm{~m}^{2}$, bias, as reflected by median difference between reference eGFR (eGFR Ref) and eGFR simulated for each assay (eGFR Assay) was similar, ranging between -5.2 and $2.0 \mathrm{~mL} / \mathrm{min} / 1.73 \mathrm{~m}^{2}$ with MDRD equation and between -5.3 and $2.1 \mathrm{~mL} / \mathrm{min} / 1.73 \mathrm{~m}^{2}$ with CKD-EPI equation. At higher values, median difference increased with eGFR when MDRD equation was used but was reduced with CKD-EPI equation. Maximal bias with CKD-EPI equation is observed for eGFR close to $75 \mathrm{~mL} / \mathrm{min} / 1.73 \mathrm{~m}^{2}$. At $90 \mathrm{~mL} / \mathrm{min} / 1.73 \mathrm{~m}^{2}$, median differences across the assays ranged between -9.0 and $3.7 \mathrm{~mL} / \mathrm{min} / 1.73 \mathrm{~m}^{2}$ with MDRD equation and between -5.9 and $2.1 \mathrm{~mL} / \mathrm{min} / 1.73 \mathrm{~m}^{2}$ with CKD-EPI equation. Impact of imprecision is also reduced with CKD-EPI equation at higher eGFR, as represented by narrower ranges between 2.5th and 97.5th percentiles. In the range of $90-120 \mathrm{~mL} / \mathrm{min} / 1.73 \mathrm{~m}^{2}$, CKD-EPI equation and enzymatic assays allowed estimation of GFR

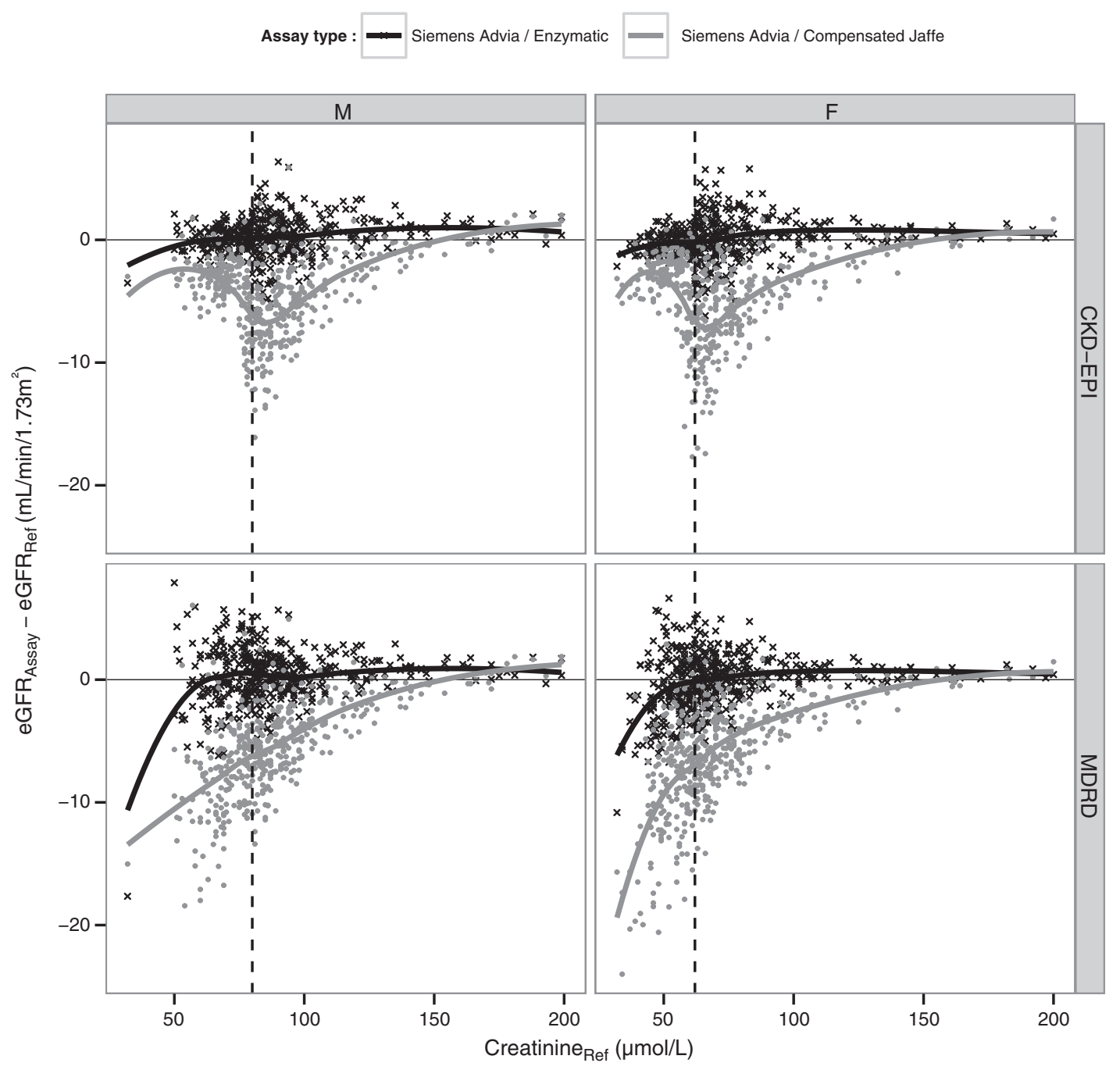

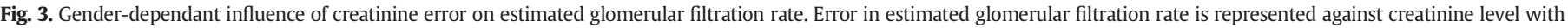

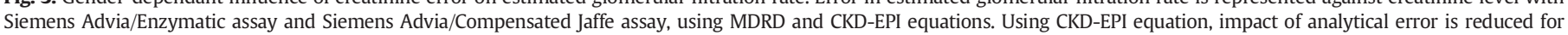
creatinine levels lower than the gender-dependant CKD-EPI threshold (62 $\mu \mathrm{mol} / \mathrm{L}$ in females and $80 \mu \mathrm{mol} / \mathrm{L}$ in males, vertical dashed lines). 
with an error below 10\% in almost all patients (mean across enzymatic assays, 98.9\%) whereas MDRD equation was more impacted by analytical error (mean across enzymatic assays, 93.8\%, Table 2 ).

\section{Discussion}

Since it has been demonstrated that mild to moderate CKD is associated with adverse clinical outcomes [12], the KDIGO working group recently decided not to combine stage 1-2 CKD [1]. Furthermore, reliable estimates of high eGFR are important for drug dosing [13]. A precise eGFR above $60 \mathrm{~mL} / \mathrm{min} / 1.73 \mathrm{~m}^{2}$ is thus valuable, which led to the development of the CKD-EPI equation. In this study, our goal was to determinate if the errors due to the Scr measurement were low enough to allow the laboratories to report numerical eGFR above $60 \mathrm{~mL} / \mathrm{min} / 1.73 \mathrm{~m}^{2}$. This study is thus an analytical study with important clinical implications.

The studies performed by the SFBC working group have highlighted the improvement of Scr measurement using enzymatic assays but also pointed out that compensated Jaffe assays do not reach the required performances [6,7]. Our results extend these observations by focusing on the consequences on eGFR. Among the 16 assays tested, compensated Jaffe assays are characterized by poorer performances than their enzymatic counterparts. The design of the SFBC study, which allowed different assays to be evaluated on the same analyzer, permits to draw conclusions about assays independently of the analytic platform. In this study, Siemens enzymatic reagent with the Siemens Advia analyzer provided reliable results whereas the compensated Jaffe assay with the same analyzer yielded deeply biased results. Furthermore, 3 of the 4 compensated Jaffe assays tested (compensated Jaffe on Siemens Advia, Roche Modular and Roche Cobas 6000 analyzers) displayed an important negative bias for eGFR in the range of $60-90 \mathrm{~mL} / \mathrm{min} / 1.73 \mathrm{~m}^{2}$, as a result of an overestimation of Scr level. This pattern underscores the difficulty for the manufacturers in correctly realigning theses assays against the IDMS reference method. The necessity of this realignment pertains to the well known interference of ketones, glucose and proteins with the Jaffe reaction [14]. Almost all the available assays are now supposed to be traceable to IDMS. Nevertheless, our results indicate that all assays are not equivalent. Surprisingly, little attention has been paid to this question in a recent KDIGO conferences report $[10,15]$. Our results are in line with previous studies concluding that compensated Jaffe assays should be replaced by enzymatic ones $[9,16]$. Conversely, a large proportion of enzymatic assays allow error in eGFR determination lower than $10 \%$ up to $90 \mathrm{~mL} / \mathrm{min} / 1.73 \mathrm{~m}^{2}$ using both MDRD and CKDEPI equations (Table 2). Enzymatic method allows reporting MDRD results numerically until $90 \mathrm{~mL} / \mathrm{min} / 1.73 \mathrm{~m}^{2}$ which is an improvement compared to prior recommendation of the NKDEP [5].

Our study also demonstrates that the impact of Scr analytical error depends on the equation used. CKD-EPI drastically decreases the impact of Scr measurement error at eGFR above $90 \mathrm{~mL} / \mathrm{min} / 1.73 \mathrm{~m}^{2}$. Maximal susceptibility to analytical error is for Scr close to the threshold between the two slopes, $62 \mu \mathrm{mol} / \mathrm{L}$ in females and $80 \mu \mathrm{mol} / \mathrm{L}$ in males, which correspond to eGFR of $120 \mathrm{~mL} / \mathrm{min} / 1.73 \mathrm{~m}^{2}$ at age 20 and $75 \mathrm{~mL} / \mathrm{min} / 1.73 \mathrm{~m}^{2}$ at age 90 (Fig. 3). This observation comes from the mathematical model used to develop the equation. The lower exponent applied to Scr values makes the eGFR far less impacted by the Scr measurement error (Fig. 4, Panel A) and explains the lower
A

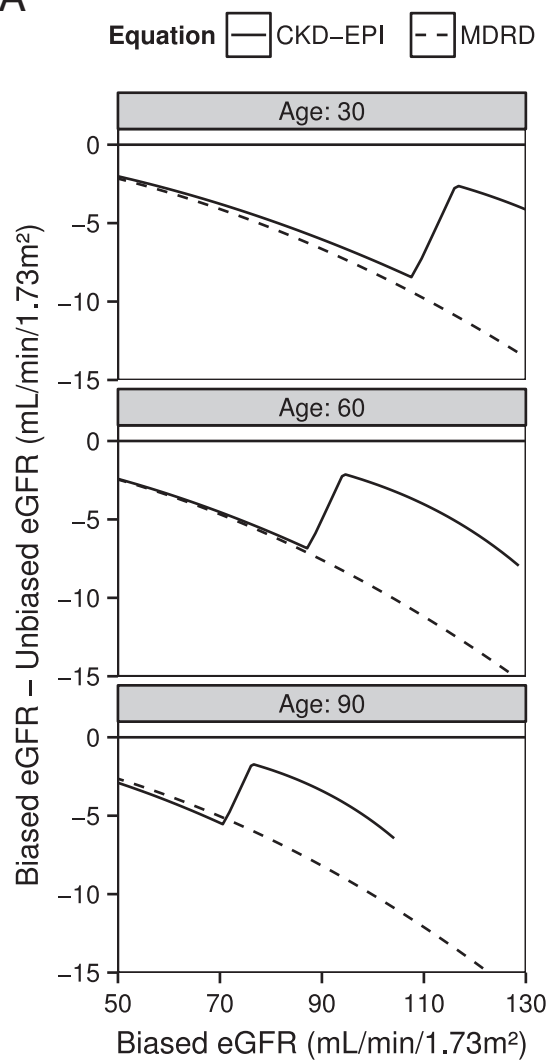

B

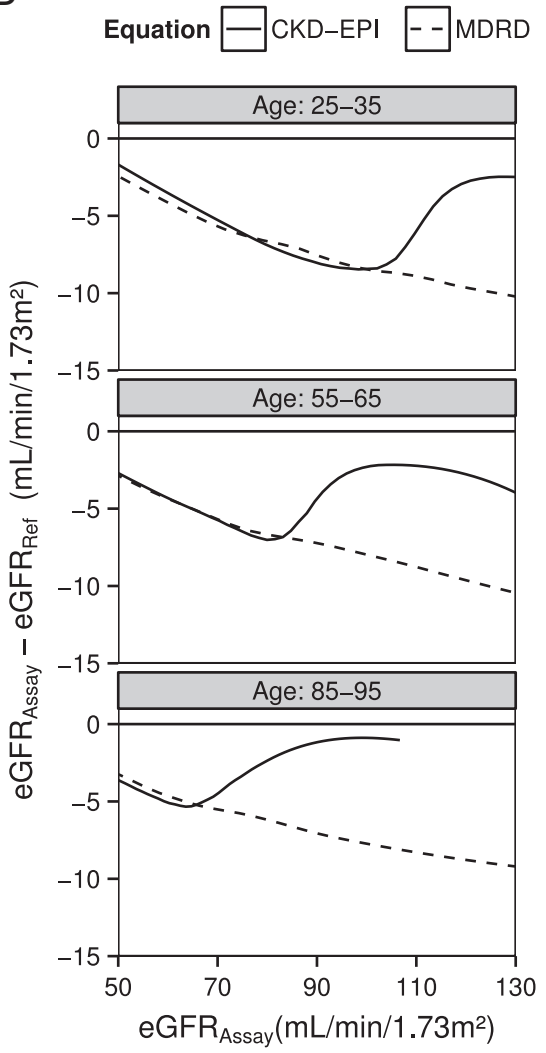

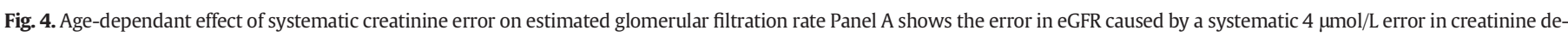

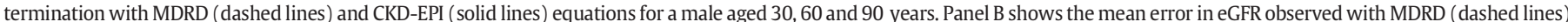

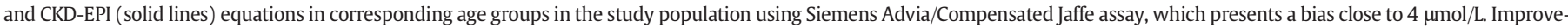

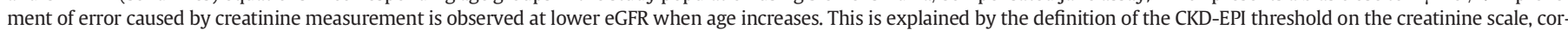
responding to age-dependant eGFR. 
error at higher eGFR levels observed in our study (Fig. 4, Panel B). Noteworthy, because the eGFR corresponding to the CKD-EPI threshold depends on age, improved robustness is mainly significant in patients aged 60 or older. The use of CKD-EPI equation in our population leads to a reduction of both bias and imprecision for eGFR higher than $90 \mathrm{~mL} / \mathrm{min} / 1.73 \mathrm{~m}^{2}$, therefore allowing estimation of eGFR up to $120 \mathrm{~mL} / \mathrm{min} / 1.73 \mathrm{~m}^{2}$.

NKDEP recommendations suggest laboratory to provide GFR estimation along with Scr results [5,17]. Little is known about the impact of analytical Scr determination on CKD-EPI equation, particularly at higher GFR. This study allows an estimation of variations of eGFR caused by analytical errors with a wide panel of assays in a large hospital-based population. Some limitations must nevertheless be acknowledged. Mainly, no GFR measured by reference methods was used and therefore impact of analytical variations could only be assessed beside eGFR calculated from IDMS Scr level. Our study showed potential superiority for the CKD-EPI equation in terms of precision compared to the MDRD one. However, this superiority is both analytical and theoretical.

In other words, we showed that enzymatic methods allow giving numerical results with the MDRD equation until $90 \mathrm{~mL} / \mathrm{min} / 1.73 \mathrm{~m}^{2}$. This does not mean that this result is clinically accurate, for example in comparison with measured GFR and in fact this equation has been shown to underestimate "true" GFR in high GFR values. In the same vein, the superiority of the CKD-EPI equation over MDRD is purely analytical and has not been confirmed by all authors [18]. Moreover, the added analytical value of the CKD-EPI equation over the MDRD one would be relevant only in the higher CKD stage (above $90 \mathrm{~mL} / \mathrm{min} / 1.73 \mathrm{~m}^{2}$ ). We should also keep in mind that CKD-EPI equation, as well as MDRD, has been derived mainly from Scr measurement performed with Jaffe assays, secondarily realign against enzymatic assays $[4,11]$. Further studies in clinical settings may be useful in order to generalize our findings by considering together the analytical errors and the errors inherent to each equation and the errors inherent to the study of various populations.

\section{Conclusions}

Our results highlight that, despite an important effort of standardization, choice of Scr assay still greatly impacts accuracy of Scr-based eGFR. This study also confirms limitations of compensated Jaffe Scr assays.

Results of this study support the use of CKD-EPI equation rather than MDRD, allowing accurate results at eGFR above $90 \mathrm{~mL} / \mathrm{min} / 1.73 \mathrm{~m}^{2}$. Once again, the better accuracy of the CKD-EPI equation is purely analytical. One of the most recent recommendations published comes from the Australasian Creatinine Consensus Working Group which recommended the use of CKD-EPI equation and a numerical expression at least up to
$90 \mathrm{~mL} / \mathrm{min} / 1.73 \mathrm{~m}^{2}$ [19]. Our study provides a basis for such recommendations and even extends it to eGFR as high as $120 \mathrm{~mL} / \mathrm{min} / 1.73 \mathrm{~m}^{2}$, as long as an accurate enzymatic assay is used.

\section{References}

[1] Levey AS, de Jong PE, Coresh J, et al. The definition, classification, and prognosis of chronic kidney disease: a KDIGO controversies conference report. Kidney Int 2011:80:17-28.

[2] Stevens LA, Coresh J, Greene T, Levey AS. Assessing kidney function - measured and estimated glomerular filtration rate. N Engl J Med 2006;354:2473-83.

[3] Levey AS, Bosch JP, Lewis JB, Greene T, Rogers N, Roth D. A more accurate method to estimate glomerular filtration rate from serum creatinine: a new prediction equation. Modification of diet in renal disease study group. Ann Intern Med 1999;130:461-70.

[4] Levey AS, Stevens LA, Schmid CH, et al. A new equation to estimate glomerular filtration rate. Ann Intern Med 2009;150:604-12.

[5] Myers GL, Miller WG, Coresh J, et al. Recommendations for improving serum creatinine measurement: a report from the laboratory working group of the National Kidney Disease Education Program. Clin Chem 2006;52:5-18.

[6] Piéroni L, Delanaye P, Boutten A, et al. A multicentric evaluation of IDMS-traceable creatinine enzymatic assays. Clin Chim Acta 2011;412:2070-5.

[7] Boutten A, Bargnoux A-S, Carlier M-C, et al. Enzymatic but not compensated Jaffe methods reach the desirable specifications of NKDEP at normal levels of creatinine. Results of the French multicentric evaluation. Clin Chim Acta 2013;419:132-5.

[8] Cobbaert CM, Baadenhuijsen H, Weykamp CW. Prime time for enzymatic creatinine methods in pediatrics. Clin Chem 2009;55:549-58.

[9] Panteghini M. Enzymatic assays for creatinine: time for action. Clin Chem Lab Med 2008;46:567-72

[10] Levin A, Stevens PE. Summary of KDIGO guideline: behind the scenes, need for guidance, and a framework for moving forward. Kidney Int 2013. http://dx.doi.org/ 10.1038/ki.2013.192 [Epub ahead of print]

[11] Levey AS, Coresh J, Greene T, et al. Expressing the modification of diet in renal disease study equation for estimating glomerular filtration rate with standardized serum creatinine values. Clin Chem 2007:53:766-72.

[12] Poggio ED, Wang X, Greene T, Van Lente F, Hall PM. Performance of the modification of diet in renal disease and Cockcroft-Gault equations in the estimation of GFR in health and in chronic kidney disease. J Am Soc Nephrol 2005;16:459-66.

[13] Stevens LA, Nolin TD, Richardson MM, et al. Comparison of drug dosing recommendations based on measured GFR and kidney function estimating equations. Am J Kidney Dis 2009;54:33-42.

[14] Greenberg N, Roberts WL, Bachmann LM, et al. Specificity characteristics of 7 commercial creatinine measurement procedures by enzymatic and Jaffe method principles. Clin Chem 2012;58:391-401.

[15] Delanaye P, Cavalier E. Staging chronic kidney disease and estimating glomerular filtration rate: an opinion paper about the new international recommendations. Clin Chem Lab Med 2013:1-7.

[16] Drion I, Cobbaert C, Groenier KH, et al. Clinical evaluation of analytical variations in serum creatinine measurements: why laboratories should abandon Jaffe techniques. BMC Nephrol 2012;13:133.

[17] Earley A, Miskulin D, Lamb EJ, Levey AS, Uhlig K. Estimating equations for glomerular filtration rate in the era of creatinine standardization: a systematic review. Ann Intern Med 2012;156:785-95 [W-270, W-271, W-272, W-273, W-274, W-275, W-276, W-277, W-278].

[18] Delanaye P, Pottel H, Botev R, Inker LA, Levey AS. Con: Should we abandon the use of the MDRD equation in favour of the CKD-EPI equation? Nephrol Dial Transplant 2013;28:1396-403.

[19] Johnson DW, Jones GRD, Mathew TH, et al. Chronic kidney disease and automatic reporting of estimated glomerular filtration rate: new developments and revised recommendations. Med J Aust 2012;197:222-3. 